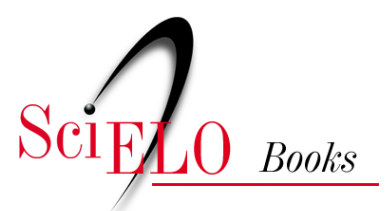

\title{
Formação econômica
}

\author{
José Carlos Radin \\ Gentil Corazza
}

\section{SciELO Books / SciELO Livros / SciELO Libros}

RADIN, J.C., and CORAZZA, G. Formação econômica. In: Dicionário histórico-social do Oeste catarinense [online]. Chapecó: Editora UFFS, 2018, pp. 60-64. ISBN: 978-85-64905-65-8.

https://doi.org/10.7476/9788564905658.0014.

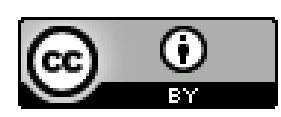

All the contents of this work, except where otherwise noted, is licensed under a Creative Commons Attribution 4.0 International license.

Todo o conteúdo deste trabalho, exceto quando houver ressalva, é publicado sob a licença Creative Commons Atribição $\underline{4.0}$.

Todo el contenido de esta obra, excepto donde se indique lo contrario, está bajo licencia de la licencia $\underline{\text { Creative Commons }}$ Reconocimento 4.0. 


\section{Formação econômica}

O processo da formação econômica da região Oeste catarinense deu-se através de uma série de fases ou ciclos, que se estendem de meados do Século XIX, com as atividades de pecuária e a ocupação dos campos, através das grandes fazendas de criar, e começam a declinar depois da metade do século XX, quando se consolida a indústria frigorífica, especialmente a de carne suína, pois a industrialização avícola só vem a acontecer duas décadas depois, por volta de 1970.

A conquista do território, em suas diferentes fases, acompanha sempre a evolução das atividades produtivas, desde a pecuária extensiva até a indústria frigorífica, permeadas pela conquista das matas com a extração da erva-mate, a atividade madeireira, o processo de colonização e o desenvolvimento peculiar da agricultura familiar, base da formação do moderno complexo agroindustrial. A formação econômica do Oeste catarinense resulta, assim, de um longo e peculiar processo histórico, cujo traço principal talvez tenha sido seu alongado isolamento e sua tardia incorporação à economia nacional.

No início de sua formação econômica, o Oeste catarinense era um corredor de passagem entre São Paulo e Rio Grande do Sul. Por ali havia sido aberto pelos tropeiros o chamado "Caminho das tropas", que conduzia o gado xucro dos campos gaúchos, para alimentar os trabalhadores do café de São Paulo e da mineração de Minas Gerais. Ao longo desses caminhos foi se dando a conquista do território pelo homem branco, através da implantação de fazendas para criar gado e do estabelecimento de novos povoados, ao lado dos que já havia na região. Nessa fase pecuária da formação econômica, além de promover a ocupação dos campos e uma maior e mais profunda penetração populacional no Oeste, a criação de gado teve pouca importância para a formação da base econômica da região. Os fazendeiros não se preocupavam em adensar a população das áreas que ocupavam, em função das dificuldades que isso implicava, deixando de povoar grande parte daquela imensa área, especialmente as matas nativas. Por isso, a agricultura pouco se desenvolveu na região nesse período. As atividades 
da pecuária tiveram mais um papel de conquista do território, uma vez que foi muito reduzida sua contribuição para a acumulação original de capital e o posterior desenvolvimento econômico regional (BAVARESCO, 2003). O capital circulante era escasso, em geral associado à comercialização de gado e de alimentos. Por volta de 1870, o ciclo da pecuária entra em declínio (RENK, 2006), juntamente com as fazendas de criar. Como consequência, as grandes fazendas se fragmentam, quer pelas heranças, quer pelas partilhas, e as populações que nelas viviam se dispersam.

Ao mesmo tempo em que se dá a conquista dos campos, vinda do Norte, processa-se a conquista das matas, pela população cabocla. O aprofundamento da conquista e ocupação do território em direção ao Oeste, saindo dos campos em direção às matas, propiciou também o descobrimento de uma nova riqueza nativa, a erva-mate, e uma nova atividade econômica, que se mostrou de fundamental importância para o desenvolvimento da região (BAVARESCO, 2003). Nos seus primórdios, a economia da erva-mate era uma atividade de coleta, nômade e extensiva, feita pela população cabocla, no interior das matas. Os caboclos, que levavam vida rudimentar, viviam em pequenos ranchos, produziam alimentos, criavam animais, porco, galinha, gado e mudavam constantemente de residência. Por isso, a extração de erva-mate nativa pode ser considerada uma atividade nômade e sazonal, entre uma poda e outra, que levava cerca de três anos. Os principais mercados consumidores da erva-mate, neste período, eram o Paraná, o Rio Grade do Sul e principalmente a Argentina. Em geral, tratava-se de um comércio quase livre, sem cobrança de impostos, devido à pouca presença e controle do governo na região. O ciclo da erva-mate, como atividade econômica relevante, foi relativamente longo (RENK, 1997), estendendo-se das últimas décadas do século XIX até o final das primeiras décadas do século XX.

Além da extração da erva-mate, a população cabocla se dedicava ao plantio de pequenas roças para a produção de alimentos necessários à sua subsistência. Esta atividade agrícola ficou conhecida como roça cabocla, que era feita em clareiras abertas na mata, através de queimadas. 
A construção da Estrada de Ferro SP-RS (EFSPRS), no início do Século XX, desempenhou um papel muito relevante para a formação econômica do Oeste catarinense. Por sua importância estratégica e pelas atividades econômicas que impulsionou, pode-se dizer que foi através dos trilhos do trem de ferro que o capitalismo chegou ao Oeste catarinense (GOULARTI FILHO, 2009).

Depois do ciclo da erva-mate veio o ciclo da madeira (BAVARESCO, 2003), que alcança seu auge entre 1930 e 1950 e termina uma década mais tarde, com o esgotamento dos pinhais de corte e de outras madeiras nobres. As atividades madeireiras, embora tenham contribuído para o povoamento e urbanização da região, através criação de vilas rurais, onde residiam os trabalhadores, não foram muito importantes para a formação inicial do capital e o desenvolvimento da região, pois os recursos por elas produzidos, eram enviados para fora, deixando de ser investidos na região. A herança que deixaram foi a devastação quase completa das matas, que antes cobriam esse imenso território.

Além de contribuir enormemente para as atividades madeireiras, a ferrovia foi uma ferrovia colonizadora, pois a história da colonização do Oeste catarinense confunde-se com a história da ferrovia (ESPIG, 2011). Assim, foi sem dúvida a partir da construção da estrada de ferro que se deu a inserção de parte da economia de Santa Catarina no mercado nacional e internacional, pois ela influenciou de maneira profunda e permanente o desenvolvimento econômico do Oeste catarinense, alterando a estrutura de propriedade das terras e a forma de exploração dos recursos naturais da região.

O ciclo da colonização e da agricultura familiar mudou os rumos da economia regional. O processo de colonização trouxe grandes transformações para o Oeste catarinense, não apenas em relação à ocupação do território, mas também no tocante às relações sociais que se desenvolveram nas novas colônias, alterando modo de vida, lazer, trabalho, uso da terra e o cotidiano cultural dos colonos. A agricultura familiar desenvolveu-se a partir da colonização, que inicia principalmente após a definição interestadual de limites e do fim da Guerra do Contestado, e se intensifica a partir de 1940, com a chegada de novas 
levas de colonos do Rio Grande do Sul, sobretudo alemães e italianos, mas também poloneses, que traziam consigo uma larga experiência no cultivo da terra. Assim, ao contrário do que havia acontecido com os ciclos anteriores da pecuária, da erva-mate e da madeira, que se mostraram incapazes de iniciar um processo de acumulação de capital na Região (BAVARESCO, 2003), a agricultura familiar contribuiu decisivamente para a formação do capital comercial e sua posterior transformação em capital industrial, base do complexo agroindustrial que se desenvolveu na região, hoje um dos polos mais dinâmicos da economia catarinense.

A formação econômica do Oeste consolida-se e se completa com a formação e o desenvolvimento do complexo frigorífico e agroindustrial. Iniciado no decorrer da década de 1940, o sistema agroindustrial ganhou impulso a partir do final da década de 1960, mas foi nos anos 1980 que esse movimento se intensificou. Esse moderno complexo agroindustrial resultou da bem-sucedida integração da agricultura familiar com a indústria frigorífica, que, por sua vez, constitui a base do atual modelo de desenvolvimento do Oeste catarinense. Nos anos 1990, houve uma profunda reestruturação na agroindústria na região, afetando as relações entre agroindústria e agricultura familiar em torno da suinocultura, provocando o abandono dessa atividade por milhares de agricultores, muitos dos quais engrossaram o fluxo migratório em direção a outras regiões. As empresas líderes, Sadia e Perdigão, efetuaram reorganizações societárias e procuraram instalar-se junto aos grandes mercados consumidores do País, assim como fortaleceram sua inserção internacional. Efetivamente, a agroindústria regional trilhou o caminho da concentração, com fusão entre Sadia e Perdigão, da qual resultou a Brasil Foods (BRF). Mais recentemente, o grupo JBS adquiriu o Seara, o Marfrig e outros frigoríficos de porte médio. Atualmente, apenas algumas poucas e grandes empresas dominam o setor, destacando-se BRF, Aurora e JBS. Todo esse processo de concentração empresarial tornou muito mais complexa a estrutura econômica e social da região. 


\section{REFERÊNCIAS}

BAVARESCO, Paulo Ricardo. Os Ciclos Econômicos do Extremo Oeste

Catarinense: modernização, progresso e empobrecimento. (Dissertação de Mestrado). Blumenau, 2003.

ESPIG, Márcia J. Personagens do Contestado: os turmeiros da Estrada de Ferro São Paulo - Rio Grande do Sul (1908-1915). Pelotas: UFPEL, 2011. GOULARTI FILHO, Alcides. Formação Econômica de Santa Catarina. Florianópolis: UFSC, 2007.

RADIN, José Carlos. Representações da Colonização. Chapecó: Argos, 2009.

RENK, Arlene. A Colonização do oeste catarinense: as representações dos brasileiros. In: CEOM: Para uma história do Oeste Catarinense: 10 anos de CEOM. Chapecó: UNOESC, 1995.

. A luta da erva: um ofício étnico no oeste catarinense. Chapecó: Grifos, 1997.

. Sociodiceia às avessas. Chapecó: Grifos, 2006. 